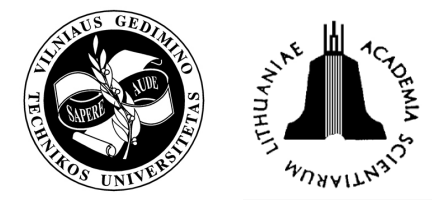

\title{
THE LINKAGE BETWEEN CLIMATE CHANGE AND ENERGY CONSUMPTION OF HUNGARY IN THE ROAD TRANSPORTATION SECTOR
}

\author{
Katalin Tanczos ${ }^{1}$, Adam Torok ${ }^{2}$ \\ Dept of Transport Economics, Budapest University of Technology and Economics, \\ H-1111 Bertalan Lajos 2; Budapest, Hungary. Phone +36-1-4631008;+36-1-463-3287 \\ E-mails: ${ }^{1}$ ktanczos@kgazd.bme.hu, ${ }^{2}$ atorok@kgazd.bme.hu \\ Received 13 November 2006; accepted 1 February 2007
}

\begin{abstract}
The aim of this article is to prove the connection between $\mathrm{CO}_{2}$ emission and climate change, and to estimate the $\mathrm{CO}_{2}$ emission of the transport sector in Hungary. We have to clarify the emission of the transport sector in order to get information on externalities, which is a further step toward a sustainable society. The sustainable development is a development, where the pace of technical development, the satiation of increasing supply and the raw materials and resources of Earth are poised so that the rate of living and opportunities of the next generations need not be worse. One of the most emphasized goals of the transport policy of the European Union is sustainable mobility. For this reason transportation systems must be developed and standardized, the effectiveness of transportation services must be increased, while the environmental pollution must be decreased or prevented. Decoupling motorization from environmental pollution is the task for engineers. Decoupling the increase of economical activity from mobility is the task for economists.
\end{abstract}

Keywords: climate change, average atmospherical $\mathrm{CO}_{2}$ concentration, transportation, $\mathrm{CO}_{2}$ emission, diesel oil, petrol, decoupling, motorization, economical activity, air pollution.

\section{Introduction}

In the last few thousand years nature gave humanity a stable base of living and gave almost infinite supply to reserve the biosphere. In early ages humanity made changes in the environment with limited technology, but the rate was infinitesimal compared to the size of the natural environment. Global changes were not detected.

In the last two or three hundred years there was an explosion in the development of industrial and technical sector, which gave people a multiplied set of tools to encroach on nature. The motorization has been developed so dynamically that the air, soil, water pollution has become considerable in the amounts of air, soil, water of Earth.

The sustainable development is a development, where the pace of technical development, the satiation of increasing supply and the raw materials and resources of Earth are poised so that the rate of living and opportunities of the next generations need not be worse.

Transportation cannot be replaced because it is the part of the production chain. Societies are horizontally and vertically differential. The manpower, the stock, the semi-finished and finished products must be transported.

The importance of the transportation sector is indicated by the sector production which is $10 \%$ of the
GDP of the European Union and more than 10 million people are working in this sector. One of the most emphasized goals of the transport policy of the European Union is sustainable mobility. For this reason transportation systems must be developed and standardized, the effectiveness of transportation services must be increased, while the environmental pollution must be decreased or prevented.

\section{Connection between climate change and transportation}

The historical records of temperature and atmospheric concentrations of $\mathrm{CO}_{2}$, methane and other greenhouse gases dating back to 420,000 years before the present were found in bubbles frozen into ice of Vostok. The ice cores were drilled into over 3,600 meters.

With common statistical tools the hypothetical trend can be discovered with the elimination of cycle effects. It means that we can apprehend not the individual, short-lasting phenomenon, but the long-range, complex effects. Examining the green-house effect we assumed that we do not need to examine the whole atmosphere, but only the relevant $\mathrm{CO}_{2}$ component. Therefore, we have examined only the average $\mathrm{CO}_{2}$ concentration in the air and the average temperature of the Earth. The graphical analysis shows that the time series can be divided into growing and into falling periods. 
Fig 1 shows the long waves of the Earth's average temperature and it can be clearly identified that the $\mathrm{CO}_{2}$ emissions show similar waves (Fig 2) [1].

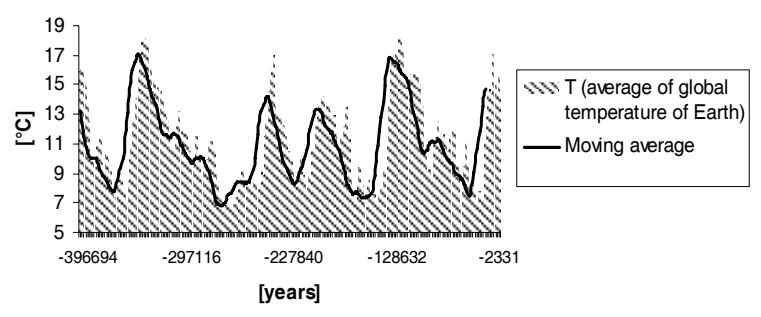

Fig 1. Time series of the global average temperature of Earth and the moving average

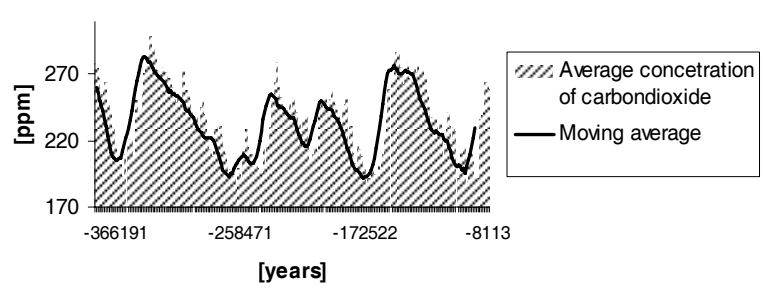

Fig 2. Time series of atmospherical carbon dioxide and the moving average

It can be seen that the moving averages represent the process and increase the deflection of certain terms, that is why we use the moving averages. We have examined the long trends of the $\mathrm{CO}_{2}$ concentration in the atmosphere and the long trends of average temperature of the Earth. It is clarified that there were no important changes in any of the trends in time.

In the periodic analysis of the average temperature of Earth we are going to analyze the decrease and increase of the average temperature. The total time series can be separated into 4 periods. All of them can be separated into a rising and a falling part. They can be compared (Fig 3).

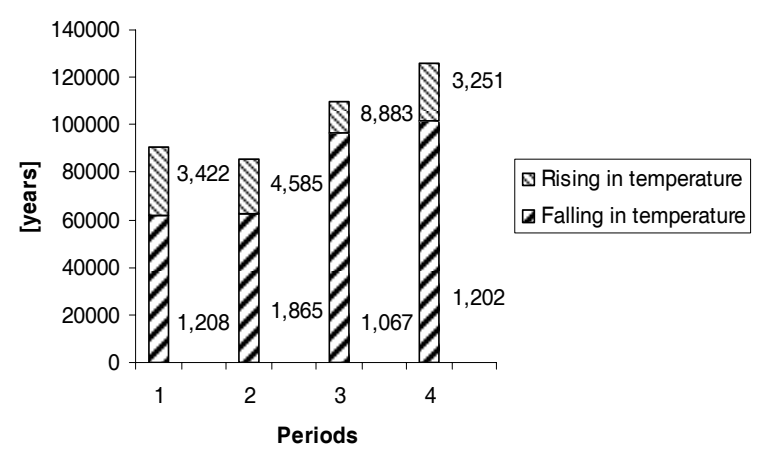

Fig 3. The bars of risings and fallings in temperature

From the results the increase of the periodic time can be estimated but because of the small amount of data the rising and falling periods cannot be compared further more. Next to the bar chart the gradient of the risings and fallings can be seen in $\left[{ }^{\circ} \mathrm{C} / 10000\right.$ years] (see Table 1).

From the data it can be seen that the risings of temperature before the human impact were 3 to 5 times faster than the fallings.
Table 1. Gradient of risings and fallings in temperature $\left[{ }^{\circ} \mathrm{C} / 10000\right.$ years $]$

\begin{tabular}{|l|c|c|}
\cline { 2 - 3 } \multicolumn{1}{c|}{} & Rising & Falling \\
\hline Maximum & 1,865 & 8,883 \\
\hline Minimum & 1,067 & 3,251 \\
\hline Average & 1,336 & 5,035 \\
\hline Deviation & 0,359 & 2,633 \\
\hline
\end{tabular}

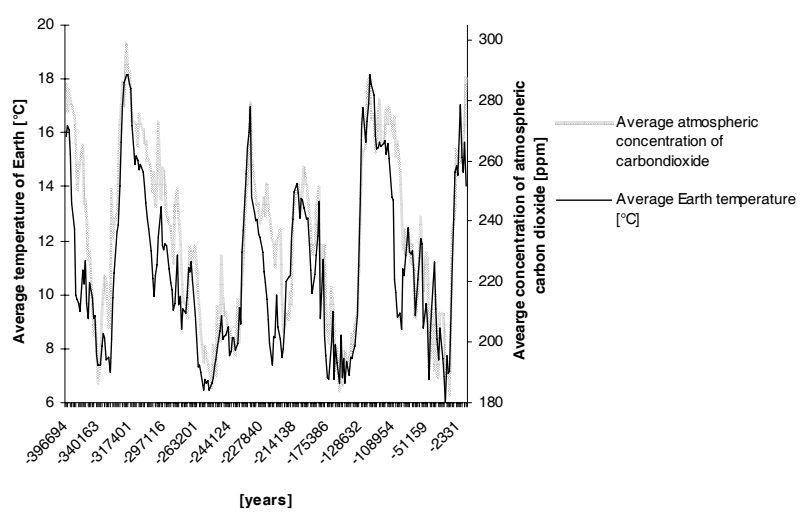

Fig 4. Normalised time series of $\mathrm{CO}_{2}$ and temperature before human impact

Our hypothesis is that there is a relation between the concentration of $\mathrm{CO}_{2}$ and the average temperature of Earth based on Fig 4. We will justify the acceptability of our hypothesis by $\chi^{2}$ test.

Our $\mathrm{H}_{0}$ hypothesis: there is a relation between atmospherical $\mathrm{CO}_{2}$ concentration and the average temperature of Earth.

Our $\mathrm{H}_{1}$ anti-hypothesis: there is no relation between atmospherical $\mathrm{CO}_{2}$ concentration and the average temperature of Earth.

Using $\chi^{2}$ test we tested the normalised values, we got that:

$$
\begin{aligned}
& \chi^{2}=\sum_{i=1}^{m} \frac{\left(f_{i}-f_{t i}\right)^{2}}{f_{t i}}=118,67 ; \\
& \chi_{c r i t(0,05 ; 238)}^{2}=247,98,
\end{aligned}
$$

where: $f_{i}$-values of atmospheric $\mathrm{CO}_{2}$ concentration; $f_{t i}$ - values of the average temperature of Earth [2].

The value of $\chi^{2}$ is less than the $\chi_{\text {crit }(0,05 ; 238)}^{2}$ (significancy level of $\alpha=5 \%$, freedom of 238), (the probability of false reject of the null hypothesis is exactly 0,05$)$. It can be declared that there is a relation between the normalised values of atmospheric $\mathrm{CO}_{2}$ concentration and the normalised values of the average temperature of Earth.

It was a great opportunity to analyse large time series, 238 data of atmospheric $\mathrm{CO}_{2}$ concentration and the average temperature of Earth. We have considered the fact that our hypothesis can be accepted only when the value of $\chi^{2}$ is less than the $\chi_{\text {crit }(0,05 ; 238)}^{2}$. We have analysed the fact that our hypothesis would be correct if 
we had only 95 data of atmospheric $\mathrm{CO}_{2}$ concentration and the average temperature of Earth instead of 238 with the same significancy level (the probability of false reject of the null hypothesis).

As we have continued our analysis we looked for the correlation between $\mathrm{CO}_{2}$ in the atmosphere and the global average temperature.

\section{Correlation}

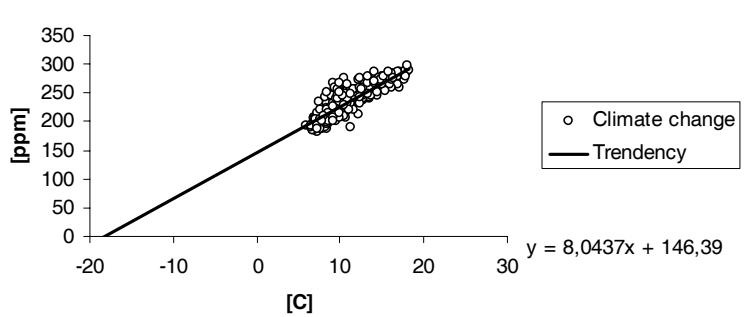

Fig 5. Atmospheric $\mathrm{CO}_{2}$ concentration in relation to average temperature of Earth

So, there is a strong correlation between atmospheric $\mathrm{CO}_{2}$ concentration and the average temperature of Earth ( $r=0,8657$, Fig 5).

Nowadays with the great human impact, that is considerable to the size of atmosphere, the relation can be changed. The $\mathrm{CO}_{2}$ emission caused by humanity raises the global temperature. More than the quarter of the total emission of $\mathrm{CO}_{2}$ caused by the humanity is produced by road transportation [3]. So, the road transportation contributes to climate change (Fig 6).

$\mathrm{CO}_{2}$ emission caused by humanity

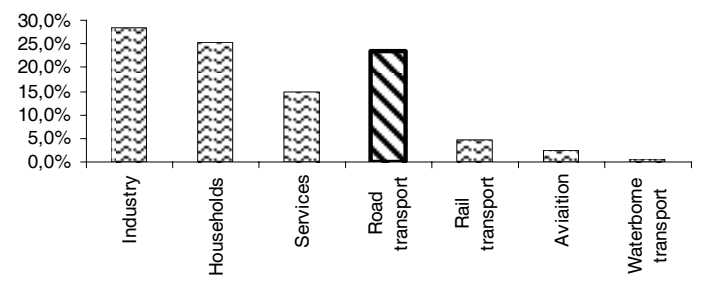

Fig 6. The road transportation contribution to climate change

There is a common, social will to protect the Earth and the environment. Climate change causes the crescendo of climate extremity in Hungary. There is a strong connection between the environment and road transportation. Road transportation has effect on the environment by emitting pollutants and greenhouse gases, but the environment has also effect on road transportation through climate change. From this point of view transportation has to hold on in this dynamic space. It has to fulfil the challenge of environment, society and economy.

\section{Estimation of $\mathrm{CO}_{2}$ emission in Hungary in the transport sector}

The base of estimation method is that we assume that there is perfect burning, altough we know that in reality just less $\mathrm{CO}_{2}$ can be produced, because there is no perfect burning. In our model we assume that because of the $\mathrm{C}$ and $\mathrm{H}$ ratio of petrol we can use octane:

$$
\mathrm{C}_{8} \mathrm{H}_{18}+\frac{25}{2} \mathrm{O}_{2} \rightarrow 8 \mathrm{CO}_{2}+9 \mathrm{H}_{2} \mathrm{O} \text {. }
$$

Because of the $\mathrm{C}$ and $\mathrm{H}$ ratio of diesel oil we can use:

$$
\mathrm{C}_{14} \mathrm{H}_{30}+\frac{43}{2} \mathrm{O}_{2} \rightarrow 14 \mathrm{CO}_{2}+15 \mathrm{H}_{2} \mathrm{O}
$$

That means, from $1 \mathrm{~mol}$, which is $114 \mathrm{~g}$ of petrol there will be after perfect burning $8 \mathrm{~mol}$, that is $352 \mathrm{~g}$ carbon dioxide. From $1 \mathrm{~mol}$, that is $198 \mathrm{~g}$ of diesel oil there will be after perfect burning $14 \mathrm{~mol}$ that is $616 \mathrm{~g}$ carbon dioxide. If we take into account the density of petrol and diesel oil we can calculate maximum amount of $\mathrm{CO}_{2}$ when 1 litre of petrol or diesel oil has been burnt (see Table 2).

We consider that Hungary has fuel consumption that can be seen in Table 3 and diesel oil consumption that can be seen in Table 4 .

Table 2. Estimation of carbon dioxide emission when burning petrol or diesel oil

\begin{tabular}{|l|c|c|}
\cline { 2 - 3 } \multicolumn{1}{c|}{} & Fuel [1] & $\mathrm{CO}_{2}$ emission[kg] \\
\hline Petrol & 1 & 2,161 \\
\hline Diesel oil & 1 & 2,489 \\
\hline
\end{tabular}

Table 3. Change of petrol consumption in time in Hungary [kilotons]

\begin{tabular}{|c|c|c|c|c|}
\cline { 2 - 5 } \multicolumn{1}{c|}{$\begin{array}{l}\text { Quality } \\
\text { (RON) }\end{array}$} & 2000 & 2001 & 2002 & 2003 \\
\hline 91 & 175 & 142 & 111 & 80 \\
\hline 95 & 927 & 1022 & 1062 & 1187 \\
\hline 98 & 231 & 208 & 176 & 165 \\
\hline Total & 1333 & 1372 & 1349 & 1432 \\
\hline
\end{tabular}

Table 4. Change of diesel oil consumption in time in Hungary [kilotons]

\begin{tabular}{|c|c|c|c|c|}
\cline { 2 - 5 } & 2000 & 2001 & 2002 & 2003 \\
\hline Diesel oil for motors & 1837 & 1908 & 1995 & 1951 \\
\hline
\end{tabular}

From this we can calculate that in 2003 Hungary had the total of 10.5 megatons of carbon dioxide emission.

\section{Linkage between economic activity, air pollution and motorization}

There is a great disharmony between the modern society that requires more and more mobility and the common will of protecting our environment. The increase in economic activity - presented by GDP [USD/person/year] causes mobility demand - presented by motorisation [PCU/1000 inhabitant] and increases environmental pollution - presented by [tC/inhabitant/year]. PCU - passenger car unit.

The time series data were available from International Monetary Found, Energy Information Administration, and Eurostat (For the modeling data of Austria, Belgium, Finland, France, Greece, Netherlands, Luxemburg, Germany, Italy, Portugal, Spain, Hungary between 1993 and 2003 has been used). We have made 
the average by nations to get the trend of the phenomenon. Regarding the correlation analysis, there is a strong correlation between the GDP and motorisation $(r=0,7877)$, and in the linear regression analysis we got the result that the elasticity of GDP to motorisation is: 0,0094 (Fig 7).

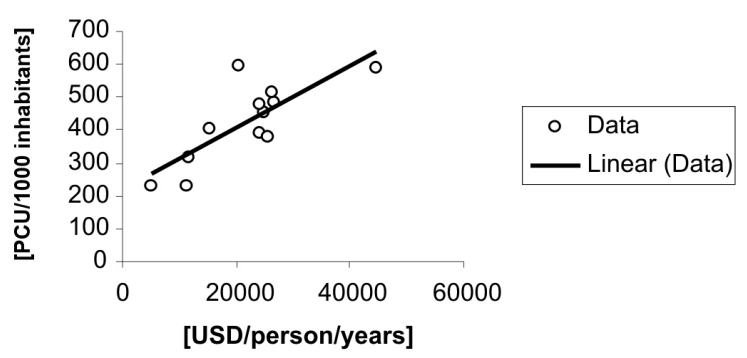

Fig 7. Relationship between GDP and motorisation

We have found that there is a strong correlation between economic activity and environmental pollution. That means that the increasing economic activity has a positive effect on living standards and a negative effect on environmental pollution as well (Fig 8).

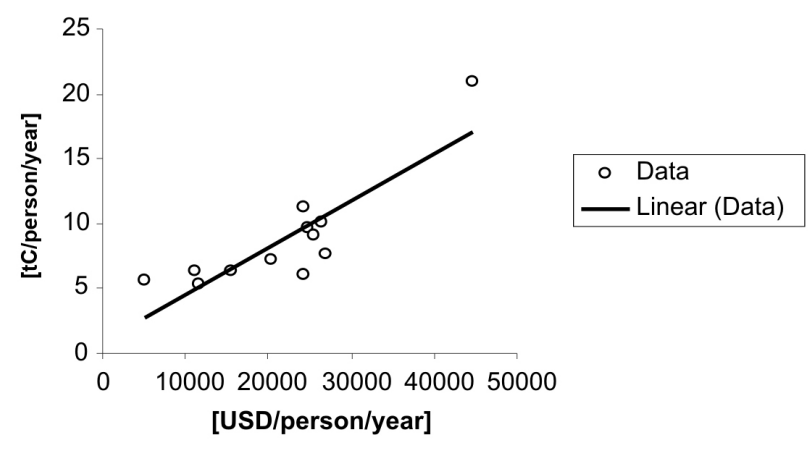

Fig 8. Relation between GDP and air pollution

We have found that the elasticity of environmental pollution to motorisation is: 0,019 . That means $1 \%$ change in motorisation in the EU causes 0,019\% change in total carbon emission (Fig 9).

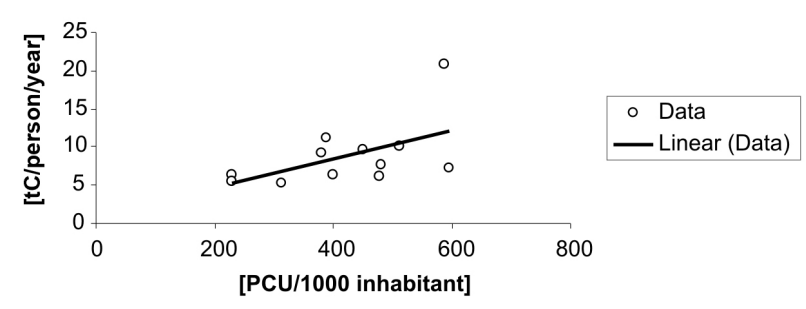

Fig 9. Relationship between motorization and air pollution

We have modeled (5) the linear relationship between economic activity, transport activity and air pollution (Fig 10):

$$
A P=f(G D P, \operatorname{MOT}(G D P)),
$$

where: $A P$ - air pollution; $G D P$ - gross domestic product (economic activity); MOT - motorisation (transport activity).
Growth in economic activity and growth in transport activity are strongly correlated. The causal relationships between the two may not be well understood; i.e., there may be uncertainty as to whether economic activity causes transport activity or transport activity causes economic activity (or both occur). Whatever the causal relationships, if any, decoupling the two would be desirable so that economic growth continues but transport growth does not, so as a result of decoupling economic growth continues but environmental pollution growth does not.

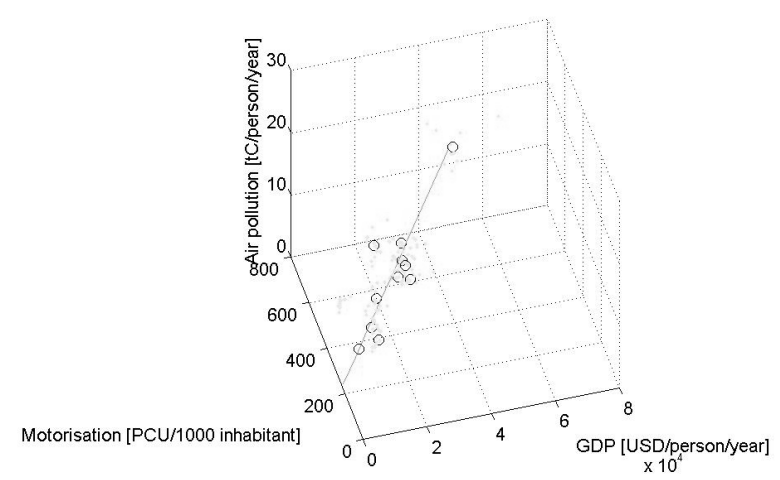

Fig. 10. Relationship between economic activity, motorisation and air pollution

We have also modeled, (6) the linear relationship after decoupling between the economic activity, mobility and air pollution, where there was no correlation between economic activity and mobility (Fig 11):

$$
A P=f(G D P, M O T),
$$

where: $A P$ - air pollution; $G D P$ - gross domestic product (economic activity); MOT - motorisation (transport activity).

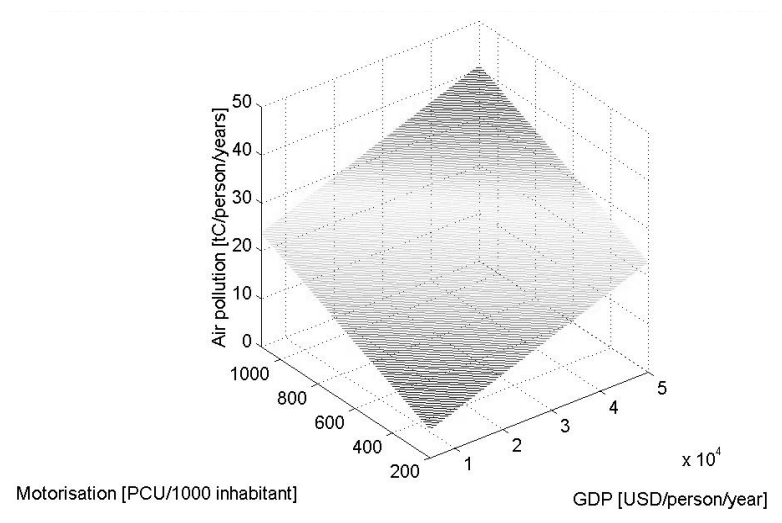

Fig 11. Complex analysis of relationship between economic activity, motorisation and air pollution after decoupling

One solution for decoupling the motorisation from environmental pollution would be the usage of alternative energy sources, biofuels. Biofuels have the advantage to emit less pollutants (Fig 12).

Another advantage of biofuels is increasing the diversification of the energy matrix and reducing the reliance on fossil fuel. That will impact energy security i.e. the availability of energy at all times, in sufficient 
quantities and at affordable prices. These conditions must prevail in the long term if energy is to contribute to sustainable development. This is a critical subject because of the uneven distribution of fossil fuel resources among countries [3].

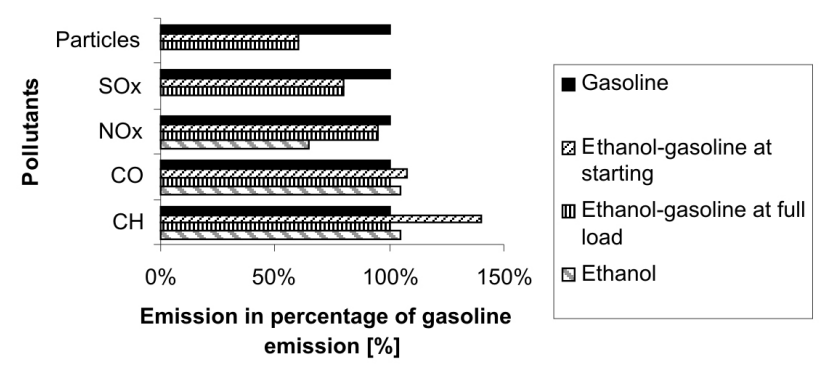

Fig 12. Comparison of emissions of ethanol and diesel oil [3]

The World Energy Assessment (WEA) has pointed out that: "views on the long-term availability of oil and natural gas continue to spark controversy and debate" (UNDP, UNDESA, WEC, 2002). Current trends indicate that the world will continue to depend on fossil fuels for decades to come, with the largest share of the world's oil resources concentrated in a few areas of the globe. Nuclear fuels are also concentrated in a few countries and nuclear technology raises concerns related to the physical security and environmental aspects of their use.

World market prices for conventional energy sources, in particular oil, are quite volatile. This poses great risks for the world's economic and political stability, with (sometimes) dramatic effects on energy-importing developing countries. In this context, renewable energies, including biofuels, can help diversify energy supply and increase energy security.

\section{Conclusion}

1. The high ratio of $\mathrm{CO}_{2}$ emission in road transportation caused by the humanity made reasonable the research of relation between the road transportation and climate change.

2. There is a justifiable demand by the society to moderate the environmental impacts caused by road transportation. Before human impact on the atmosphere there was relation between the concentration of atmospherical $\mathrm{CO}_{2}$ and global average temperature.

3 . Nowadays with the human impact on the atmosphere the relation can be modified and that causes changes in our climate.

4. Nowadays there are approved scientifical techniques to calculate social marginal cost of road transportation and to bring equilibrium between transport modes. However the most flexible way of transportation is the road transportation, the marginal social cost of road transportation is high and needs to be monetarised in a harmonised way and shifted to the users.

\section{References}

1. PETIT, J. R.; JOUZEL, J.; RAYNAUD, D. et al. Climate and atmospheric history of the past 420,000 years from the Vostok ice core, Antarctica. Nature, 1999, Vol 399, No 6735, p. 429-436.

2. MAGYAR, I.; VÁRLAKI, P. Statistics (Statisztika). Budapest: Tankönyvkiadó, 1982 (in Hungarian).

3. ZÖLDY, M. The changes of burning efficiency, emission and power output of a Diesel engine fuelled by bioethanol - biodiesel-diesel oil mixtures. In Complete Proceedings of the FISITA 2006 World Automotive Congress held from 22-27 October in Yokohama, Japan. JSAE: 2006, ISBN 4-915219-83-6 (CD-ROM). 